\title{
Primary Colonic Signet Ring Cell Carcinoma Presenting Carcinocythemia: An Autopsy Case
}

\author{
Ryosuke Misawa ${ }^{a}$ Motohiro Kobayashi ${ }^{b}$ Makoto Ito ${ }^{c}$ \\ Mai Kato ${ }^{d}$ Yuji Uchikawa ${ }^{a}$ Satoshi Takagi ${ }^{a}$ \\ aDepartment of Surgery, Omachi Municipal General Hospital, Omachi, \\ ${ }^{b}$ Department of Molecular Pathology, Shinshu University Graduate School of \\ Medicine, Matsumoto, 'Department of Pathology and Laboratory Medicine, Kariya \\ Toyota General Hospital, Kariya, and dDepartment of Laboratory Medicine, \\ Shinshu University Hospital, Matsumoto, Japan
}

\section{Key Words}

Signet ring cell carcinoma $\cdot$ Colon $\cdot$ Carcinocythemia $\cdot$ Disseminated intravascular coagulation

\begin{abstract}
Primary colorectal signet ring cell carcinoma (SRCC) is a rare but distinctive type of mucin-producing adenocarcinoma of the large intestine with still controversial clinicopathological features and prognosis. We encountered primary colonic SRCC in a 51-year-old Japanese man with extensive bone metastasis ultimately leading to carcinocythemia before the initiation of chemotherapy and surgical intervention. Three days before death, besides progressive disseminated intravascular coagulation that had been present on admission, hematological examination showed sudden leukocytosis with nonhematopoietic cells that subsequently turned out to be signet ring cells (SRCs). Carcinocythemia, the presence of circulating cancer cells in peripheral blood, is considered to be a rare but an ominous phenomenon occurring in the advanced stage of certain types of cancers, particularly mammary lobular carcinoma. It can be assumed that carcinoma cells lacking intercellular cohesiveness and polarized cell membrane organization, including SRCs as well as lobular carcinoma cells, can readily get access to the peripheral circulation; however, to our knowledge, this is the first report of primary colorectal SRCC that presented carcinocythemia. Extensive bone metastatic sites, in the present case, may have functioned as a reservoir of circulating SRCs.
\end{abstract}




\section{Introduction}

Primary colorectal signet ring cell carcinoma (SRCC), first described by Laufman and Saphir in 1951 [1], is a rare but distinctive histological type of colorectal adenocarcinoma that accounts for less than $1 \%$ of all colorectal malignancies [2-4]. SRCC is a mucin-producing adenocarcinoma whose cells retain intracytoplasmic mucin, pushing their nuclei to the periphery [4]. Signet ring cells (SRCs) may be arranged solely or in loose clusters and may spread diffusely through the colorectal wall [3]. Since the vast majority of SRCCs arise in the stomach with the rest arising from other organs, including the colon, rectum, gallbladder, pancreas, urinary bladder, and breast [5], metastatic SRCCs must be excluded before making the definite diagnosis of primary colorectal SRCC. It is of little doubt that primary colorectal SRCC has a poor prognosis; however, most studies so far have demonstrated controversial results for clinicopathological features and prognosis of primary colorectal SRCC $[2-4,6,7]$, partly because of the limited number of cases with this type of colorectal carcinoma. Hence, more studies and reports should be accumulated to more accurately characterize the biological behaviors of primary colorectal SRCC. We report here an autopsy case of primary colonic SRCC with extensive bone metastasis, ultimately leading to carcinocythemia before the initiation of chemotherapy and surgical intervention. The mechanisms underlying such a unique metastatic process will be discussed along with other hematologic and coagulative abnormalities observed in the present case.

\section{Case Report}

A 51-year-old Japanese man visited with a complaint of severe back pain. In spite of no apparent abnormal findings in lumbar roentgenogram, magnetic resonance imaging (MRI) demonstrated high signal intensity spreading diffusely in multiple vertebrae, suggesting a diffuse bone metastasis that may also simulate multiple myeloma, leukemia, myelodysplastic syndrome, and osteomyelitis (fig. 1a). To determine the possible primary lesion, systemic computed tomography (CT) scanning was performed, which detected a mass lesion in the ascending colon (fig. 1b). Subsequent colonoscopic examination revealed a type 3 tumor (fig. 1c), and histopathological examination of the biopsied specimen disclosed SRCC. Since additional endoscopic examination could not detect any cancerous lesion in the stomach, which is the most common site of SRCC, we diagnosed the colonic tumor as primary colonic SRCC.

At the same time, hematological examination showed mild thrombocytopenia $\left(12.9 \times 10^{4} / \mu \mathrm{l}\right)$ (fig. 2a), hypofibrinogenemia $(952 \mu \mathrm{g} / \mathrm{ml})$, and elevated fibrin/fibrinogen degradation products $(69.4 \mu \mathrm{g} / \mathrm{ml})$ and D-dimer $(61.5 \mu \mathrm{g} / \mathrm{ml})$ (fig. $2 \mathrm{~b})$, which were, as a whole, suggestive of disseminated intravascular coagulation. Elevated levels of serum alkaline phosphatase (ALP) (750 IU/l) and lactate dehydrogenase (LDH) (1,226 IU/l) (fig. 2c), in addition to carcinoembryonic antigen $(21.1 \mathrm{ng} / \mathrm{ml})$ and carbohydrate antigen 19-9 (79.3 U/ml), were also detected. Considering possible future chemotherapy, heparin and gabexate mesilate were administered; however, the patient's clinical condition rapidly deteriorated without any chance for chemotherapy. On the 22nd day after admission, hematological examination showed sudden leukocytosis $(25,200 / \mu \mathrm{l})$ (fig. $2 \mathrm{~d}$ ) with approximately $1 \%$ of nonhematopoietic cells in addition to abrupt elevation of serum ALP (1,085 IU/l), LDH (4,769 IU/l) (fig. 2c), and C-reactive protein (CRP) $(23.4 \mu \mathrm{g} / \mathrm{ml})$ levels (fig. $2 \mathrm{~d})$. Subsequent cytological examination disclosed that those nonhematopoietic cells (ig. 3 a) harbored periodic acid-Schiff (PAS)-positive mucin inside the cells (fig. 3b) and were also positive for cytokeratin (CK) CAM5.2 (Becton Dickinson, San Jose, CA, USA) (fig. 3c) [8], indicating these cells were SRCs originating from the colonic tumor. The patient died of multiple organ failure on the 25 th day after admission.

Postmortem examination restricted to abdominal organs was carried out with permission. Macroscopically, the colonic tumor was a whitish ulcerative type 3 tumor, measuring $50 \times 35 \mathrm{~mm}$, invading predominantly the subserosa and adjacent mesenteric lymph nodes, and disseminated to the peritoneal cavity to form multiple whitish nodules up to $3 \mathrm{~mm}$ in diameter. Apparent macrometastases were not detected in other visceral organs such as liver, spleen, and kidneys. 
Histologically, the colonic tumor consisted of a diffuse infiltration with frequent lymphatic invasion of SRCs (fig. 3d) harboring abundant Alcian blue (AB)- or PAS-positive mucin pushing their nuclei to the periphery (fig. 3e), and diffusely spread throughout the colonic wall with predominance of subserosa. Distant metastasis was detected in lumbar vertebrae, whose marrow cavity was almost exclusively occupied with SRCs (fig. 3f). Interestingly, while apparent tumors or nodules were not detected in the liver, numbers of SRCs infiltrated hepatic sinusoids, mimicking leukemic infiltration without any alteration of the hepatic parenchyma (fig. 3g). A small number of SRCs was detected in the marginal sinus of the spleen as well. In addition to the fact that precise histological examination of the stomach failed to detect any primary gastric SRCC, colonic SRCs were immunohistochemically positive for CDX2 (CDX2-88; BioGenex, San Ramon, CA, USA) (fig. 3h) [9], negative for CK 7 (OV-TL 12/30; Dako, Kyoto, Japan) (fig. 3i), focally positive for CK 20 (Ks20.8; Dako) (fig. 3j) [10], positive for MUC2 (Ccp58; Novocastra, Newcastle upon Tyne, UK) (fig. 3k), and focally positive for MUC5AC (CLH2; Novocastra) (fig. 3l) $[11,12]$. These findings combined allowed us to diagnose the colonic tumor as primary colonic SRCC.

\section{Discussion}

In spite of controversial results for clinicopathological features and prognosis [2-4, $6,7]$, primary colorectal SRCC is generally considered to have a poor prognosis partly due to its (i) diffuse intramural infiltration, (ii) lymph node involvement, and (iii) peritoneal dissemination, and therefore (iv) advanced disease (stage III or IV) at the time of diagnosis and (v) lower rate of curative resection $[5,12]$.

To exclude metastatic SRCC from other organs, particularly that of the stomach, we performed immunohistochemistry for a battery of antigens besides precise histological examination of the stomach, which failed to detect any primary gastric SRCC. CDX2, a homeodomain protein involved in the regulation of intestinal development and differentiation, is expressed in the nuclei of epithelial cells throughout the intestine and has been demonstrated in all cases of colorectal adenocarcinomas and almost $50 \%$ of gastric adenocarcinomas [9]. The CK 7(-)/CK 20(+) profile of the carcinoma cells favors the colorectal neoplasms rather than those arising in the stomach, pancreatobiliary tract, breast, and prostate [10]. Additionally, among the mucin core proteins, MUC2 and MUC5AC are expressed in the intestinal and gastric mucosa, respectively [11]. In the present case, some population of the SRCs exhibited an aberrant expression of MUC5AC, which implied a phenotypic diversity of mucin-secreting tumors.

We report here an autopsy case of primary colonic SRCC characterized by the occurrence of carcinocythemia in the terminal stage. Three days before death, hematological examination showed sudden leukocytosis with nonhematopoietic cells that subsequently turned out to be SRCs. It should be argued whether the SRCs could directly permeate into the peripheral circulation from the primary site. In this case, the lymphatic invasion was more pronounced than vascular invasion in the colonic tumor. Even though a certain number of SRCs may transiently circulate in the peripheral blood, such tumor cells may be destroyed by natural killer cells or other tumor-specific cytotoxic response, or may escape from the circulation to form metastatic tumors in the distant organs. Excess in population of the tumor cells in the bone marrow overwhelming the capacity of reticuloendothelial clearance can flood into the peripheral circulation at the terminal stage of cancer [13].

In this case, it can be assumed that the bone metastatic sites behave as a reservoir of circulating SRCs. Colonic SRCs may find a way to metastasize to the distant site via the lymphatic or hematogenous pathways, then migrate and colonize in the bone marrow sinus, where the SRCs occupy the sinusoidal space from which the cancer cells flood into the peripheral circulation. Carcinocythemia, a term introduced by Carey et al. in 1976 


\begin{tabular}{r|l|l|l} 
Case Reports $h$ & $\begin{array}{l}\text { Case Rep Gastroenterol 2008;2:301-307 } \\
\text { D01: 10.1159/000155146 }\end{array}$ & Published online: September 30, 2008 & $\begin{array}{l}\text { O 2008 S. Karger AG, Basel } \\
\text { ISSN 1662-0631 } \\
\text { www.karger.com/crg }\end{array}$ \\
\hline
\end{tabular}

[14], is known as a unique form of cancer metastasis in which the cancer cells can be detected in the peripheral blood, generally occurring in far advanced stage of certain malignant neoplasms such as breast cancer, small cell carcinoma, and rhabdomyosarcoma [15]. In particular, it is noteworthy that mammary lobular carcinoma has a potential propensity for bone metastasis and subsequent carcinocythemia [13]. Carcinoma cells lacking intercellular cohesiveness and polarized cell membrane organization, including SRCs as well as lobular carcinoma cells, can readily get access to the peripheral circulation; however, as far as we know, this is the first report of colorectal SRCC that presented carcinocythemia.

In conclusion, we report an autopsy case of primary colonic SRCC with extensive bone metastasis, ultimately leading to carcinocythemia with disseminated intravascular coagulation, which deprived us of any chance for chemotherapy and surgical intervention. Carcinocythemia, the presence of circulating tumor cells, is considered to be a rare but an ominous phenomenon occurring in the advanced stage of cancers, including the present case.

\section{Acknowledgements}

The authors thank Drs. Masao Hotchi and Jun Nakayama for useful discussion, and Messrs. Toshiro Nishimaki and Shinichi Fujii for technical assistance.

Fig. 1. a MRI showing high signal intensity spreading diffusely in multiple vertebrae. b Systemic CT scanning showing a mass lesion in the ascending colon. c Colonoscopic examination revealing a type 3 tumor in the ascending colon.
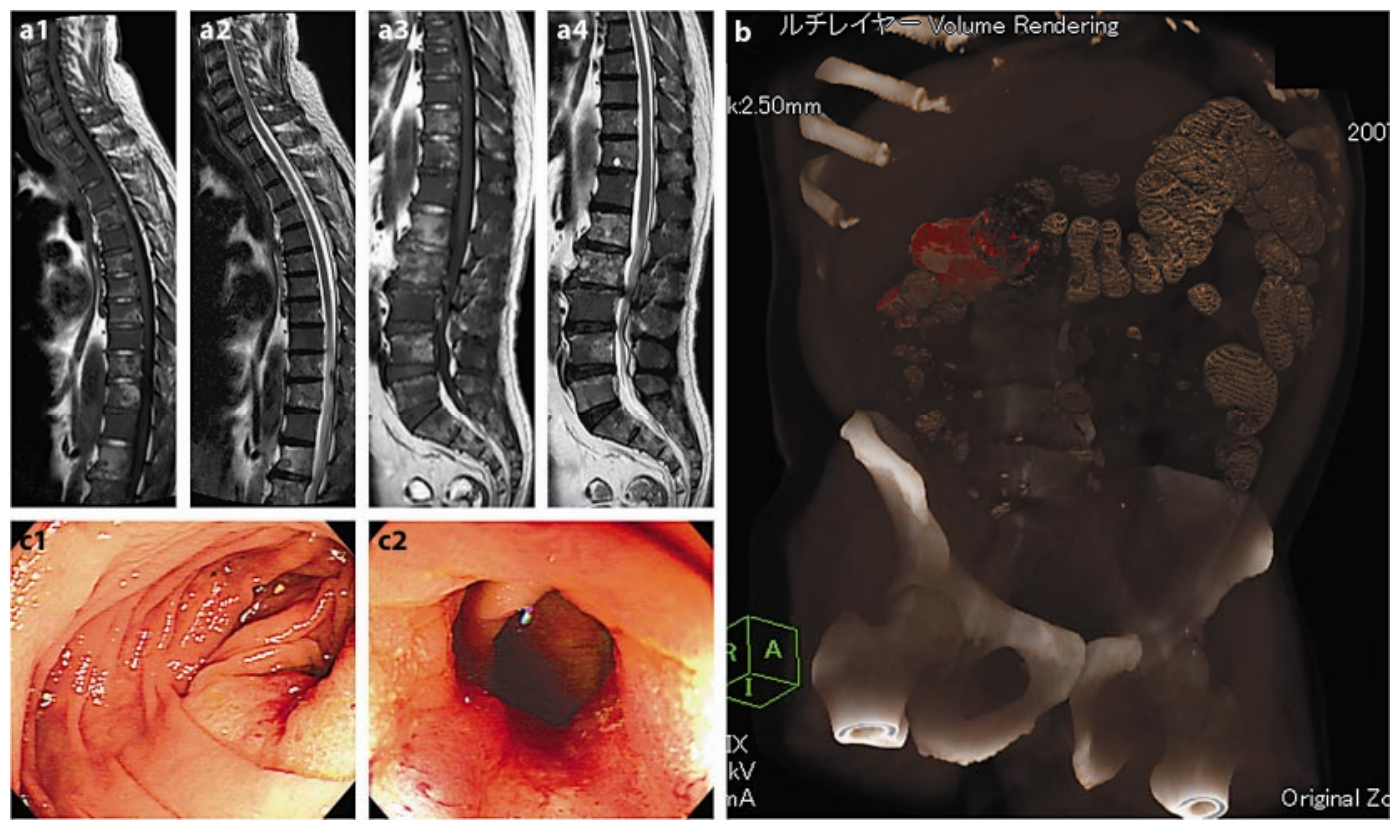
Fig. 2. Hematological examination during the course of the disease showing mild thrombocytopenia (a), hypofibrinogenemia and elevated level of D-dimer (b) and elevated levels of serum ALP and LDH (c). At the terminal stage, sudden leukocytosis and elevated CRP levels (d) with abrupt elevation of serum ALP and LDH (c) were observed.
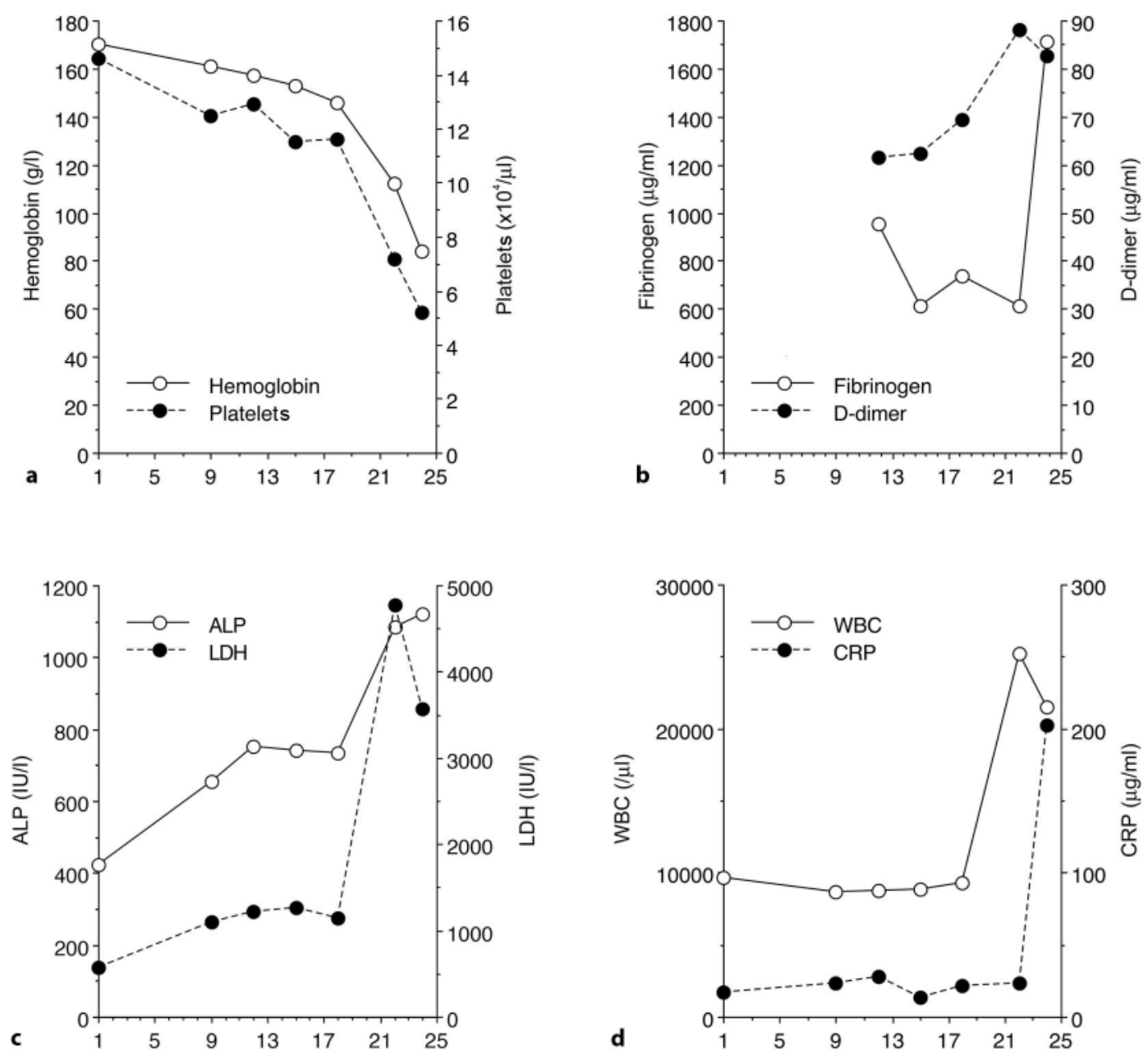


\begin{tabular}{r|l|l|l} 
Case Reports $/ \mathrm{h}$ & $\begin{array}{l}\text { Case Rep Gastroenterol 2008;2:301-307 } \\
\text { D0I: 10.1159/000155146 }\end{array}$ & Published online: September 30, 2008 & $\begin{array}{l}\text { O 2008 S. Karger AG, Basel } \\
\text { ISSN 1662-0631 } \\
\text { www.karger.com/crg }\end{array}$ \\
\hline
\end{tabular}

Fig. 3. a-c Cytological examination demonstrating nonhematopoietic cells in peripheral blood. Nonhematopoietic cells in peripheral blood appear in lose clusters (a, PAP staining), having PAS-positive mucin inside the cells pushing their nuclei to the periphery (b, PAS staining). They are immunocytochemically positive for CK CAM5.2 (c). d-I Histopathology of the specimen obtained at postmortem examination. The colonic tumor consists of a diffuse infiltration with occasional lymphatic invasion (arrowheads) of SRCs (d, HE staining) harboring abundant AB- or PAS-positive mucin inside the cells (e, AB-PAS staining). Bone marrow cavities of the lumbar vertebrae are almost exclusively occupied by the SRCs positive for CK AE1/AE3 (Dako) (f). AB-positive SRCs infiltrate hepatic sinusoids without any alteration of the hepatic parenchyma (g, AB-PAS staining). The colonic SRCs are immunohistochemically positive for CDX2 (h), negative for CK $7(\mathbf{i})$, focally positive for CK $20(\mathbf{j})$, positive for MUC2 (k), and focally positive for MUC5AC (I). Bar $=10 \mu \mathrm{m}$ for $\mathbf{a}-\mathbf{c}$ and $20 \mu \mathrm{m}$ for $\mathbf{d}-\mathbf{I}$. $\mathrm{PAP}=$ Papanicolaou; $\mathrm{HE}=$ hematoxylin and eosin.
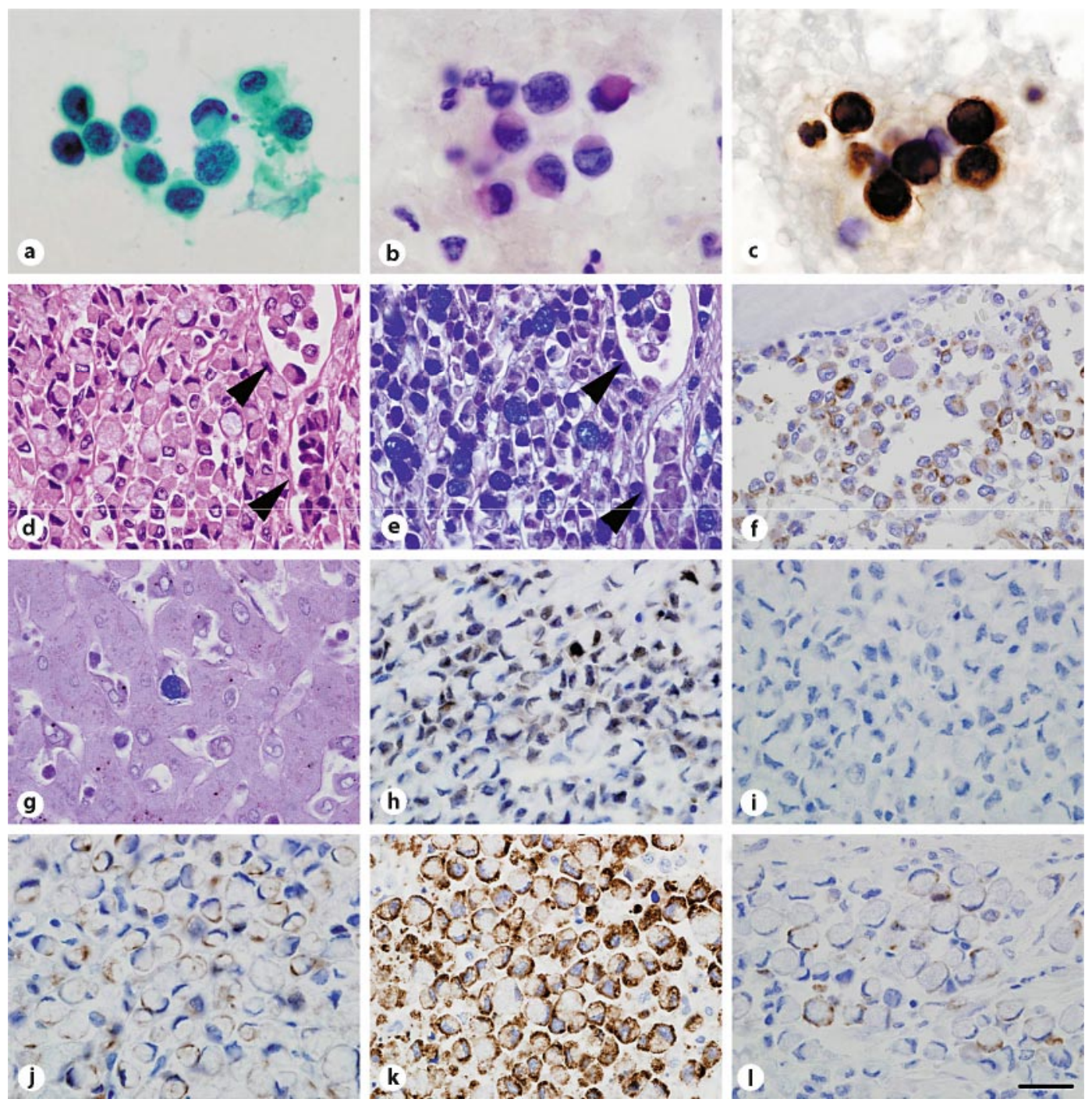


\section{References}

1 Laufman H, Saphir O: Primary linitis plastica type of carcinoma of the colon. AMA Arch Surg 1951;62:79-91.

2 Psathakis D, Schiedeck TH, Krug F, Oevermann E, Kujath P, Bruch HP: Ordinary colorectal adenocarcinoma vs. primary colorectal signet-ring cell carcinoma: study matched for age, gender, grade, and stage. Dis Colon Rectum 1999;42:16181625.

-3 Ooi BS, Ho YH, Eu KW, Seow Choen F: Primary colorectal signet-ring cell carcinoma in Singapore. ANZ J Surg 2001;71:703-706.

$\checkmark 4$ Lee WS, Chun HK, Lee WY, Yun SH, Cho YB, Yun HR, Park SH, Song SY: Treatment outcomes in patients with signet ring cell carcinoma of the colorectum. Am J Surg 2007;194:294-298.

-5 Tung SY, Wu CS, Chen PC: Primary signet ring cell carcinoma of colorectum: an age- and sex-matched controlled study. Am J Gastroenterol 1996;91:2195-2199.

-6 Messerini L, Palomba A, Zampi G: Primary signet-ring cell carcinoma of the colon and rectum. Dis Colon Rectum 1995;38:1189-1192.

7 Makino T, Tsujinaka T, Mishima H, Ikenaga M, Sawamura T, Nakamori S, Fujitani K, Hirao M, Kashiwazaki M, Masuda N, Mano M: Primary signet-ring cell carcinoma of the colon and rectum: report of eight cases and review of 154 Japanese cases. Hepatogastroenterology 2006;53:845-849.

8 Poston RN, Sidhu YS: Diagnosing tumors on routine surgical sections by immunohistochemistry: use of cytokeratin, common leucocyte, and other markers. J Clin Pathol 1986;39:514-523.

\$9 Werling RW, Yaziji H, Bacchi CE, Gown AM: CDX2, a highly sensitive and specific marker of adenocarcinomas of intestinal origin: an immunohistochemical survey of 476 primary and metastatic carcinomas. Am J Surg Pathol 2003;27:303310.

10 Goldstein NS, Long A, Kuan SF, Hart J: Colon signet ring cell adenocarcinoma: immunohistochemical characterization and comparison with gastric and typical colon adenocarcinomas. Appl Immunohistochem Mol Morphol 2000;8:183-188.

-11 Reis CA, David L, Carvalho F, Mandel U, de Bolos C, Mirgorodskaya E, Clausen $\mathrm{H}$, Sobrinho-Simoes M: Immunohistochemical study of the expression of MUC6 mucin and co-expression of other secreted mucins (MUC5AC and MUC2) in human gastric carcinomas. J Histochem Cytochem 2000;48:377-388.

12 Chu PG, Weiss LM: Immunohistochemical characterization of signet-ring cell carcinoma of the stomach, breast, and colon. Am J Clin Pathol 2004;121:884-892.

13 Myerowitz RL, Edwards PA, Sartiano GP: Carcinocythemia (carcinoma cell leukemia) due to metastatic carcinoma of the breast: report of a case. Cancer 1977;40:3107-3111.

14 Carey RW, Taft PD, Bennett JM, Kaufman S: An acute leukemia-like picture due to metastatic carcinoma cells. Am J Med 1976;60:273-278.

15 Seronie-Vivien S, Mery E, Delord JP, Fillola G, Tkaczuk J, Voigt JJ, Bugat R: Carcinocythemia as the single extension of breast cancer: report of a case and review of the literature. Ann Oncol 2001;12:1019-1022. 